\title{
Energy Harvesting in Immersed Tunnel for Powering Wireless Sensor Nodes for Corrosion Monitoring
}

This paper was downloaded from TechRxiv (https://www.techrxiv.org).

LICENSE

CC BY 4.0

SUBMISSION DATE / POSTED DATE

21-01-2022 / 03-02-2022

\section{CITATION}

Hire, Jaamac; Moradi, Farshad; Agianniotis, Nikolaos; kofoed, Brain (2022): Energy Harvesting in Immersed Tunnel for Powering Wireless Sensor Nodes for Corrosion Monitoring. TechRxiv. Preprint. https://doi.org/10.36227/techrxiv.18863714.v1

$\mathrm{DOI}$

10.36227/techrxiv.18863714.v1 


\title{
Energy Harvesting in Immersed Tunnel for Powering Wireless Sensor Nodes for Corrosion Monitoring
}

\author{
Jaamac Hassan Hire, Nikolaos Agianniotis, Brian Peter Kofoed and Farshad Moradi, Senior Member,IEEE
}

\begin{abstract}
This paper investigates the use of reinforced concrete (RC) battery for powering future Wireless Sensor Nodes (WSN) for internet of things (IOT) - monitoring the corrosion process in tunnels. Results obtained from a realworld immersed tunnel, which has hundreds of electrochemical based corrosion sensors embedded into the reinforced concrete structure, show that sufficient energy can be extracted from these electrochemical sensors to perform wireless transmissions of the corrosion potential to a base-station. With an open circuit potential of $975 \mathrm{mV}$, the maximum output power that can be extracted is $12.4 \mu \mathrm{W}$, while the minimum measured output power is $1 \mu \mathrm{W}$. The results also show that power of $8.82 \mu \mathrm{W}$, with an open circuit potential of $727 \mathrm{mV}$, can directly be extracted from the reinforcement steel itself. This makes it possible for the energy source to have a long lifetime, since the steel volume can work as a large battery anode. If the steel reinforcement (anode) is protected by an impressed cathodic protection system (CP) the induced galvanic corrosion-rate is minimum to non-exisiting.

Furthermore, performed calculations show that harvesting energy from the corrosion sensors will induce a galvanic corrosion rate of $11 \mu \mathrm{m} / \mathrm{year}$ under continious usage, while a transimission of the corrosion data once every second month, only

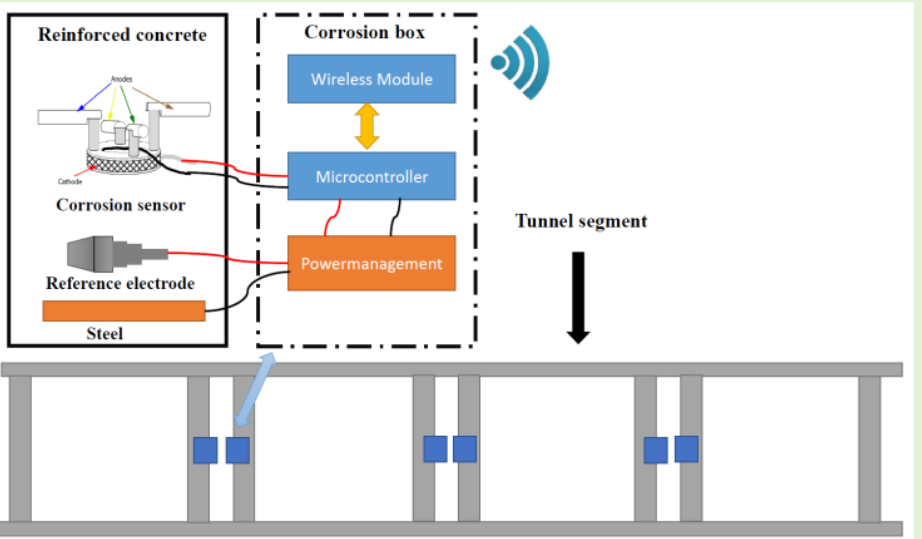
induces a (galvanic) corrosion rate of $1.83 \mu \mathrm{m} / \mathrm{year}$. This indicates that there is no risk to the structural integrity when aplying the energy source.

Index Terms- Corrosion Monitoring, Concrete battery, Energy harvesting, Reinforced Concrete, internet of things
\end{abstract}

\section{Introduction}

$\mathrm{T}$

here are around 200 immersed tunnels in the world. An immersed tunnel has many advantages, such as lower implementation cost, speed of construction and minimal disruption to a channel/river's shipping routes. With the advent of new construction techniques and technologies, immersed tunnels are set to become far more common in the coming years [1]. Currently the longest immersed tunnel is being built between Rødbyhavn, Denmark, and the German island Fehmarn, ergo called Fehmarn belt tunnel [2].

The aggressive marine environment, in which the tunnels are immersed in, can lead to premature chloride-induced corrosion of the steel reinforcement.

This paragraph of the first footnote will contain the date on which you submitted your paper for review. It will also contain support information, including sponsor and financial support acknowledgment. For example, "This work was supported in part by the Innovation fund, Denmark under File no. 8053-00200B."

Jaamac Hassan Hire is with Integrated Nanoelectronics, Department of Electrical Engineering, Aarhus University and FORCE TECHNOLOGY, 8200 Aarhus N.

Nikolaos Agianniotis is with FORCE TECHNOLOGY, 2605 Brøndby, Brian Peter Kofoed is with FORCE TECHNOLOGY, 2605 Brøndby. Farshad Moradi is with Integrated Nanoelectronics, Department of Electrical Engineering, Aarhus University, 8200 Aarhus N.
Globally, corrosion in reinforced concrete (RC) structures is a grand challenge; it is estimated that approximately 2.3 trillion euros is spent annually on remediating corrosion problems, amounting to 3-4 percent of the gross world product (GWP) [3]. Corrosion in RC can also be a huge safety hazard if not properly managed and monitored.

In August 2018, the Morandi bridge in Italy collapsed, where 43 people were killed, and more recently a condo in Miami collapsed and killed 98 people. Investigators believe that in both structural collapses, undetected corrosion have been a significant contributor [4] , [5].

Corrosion is typically defined as the destructive result of an electrochemical reaction between a metal (steel) and its environment. The corrosion of the steel reinforcement will appear in different ways, ranging from widespread uniform corrosion called general corrosion, to very localized attacks called pitting corrosion. For reinforcement in marine environment, a typical reaction with oxygen and water could be the following.

$$
\begin{gathered}
2 \mathrm{Fe} \rightarrow 2 \mathrm{Fe}^{2+}+4 e^{-}(\text {Anodic reaction }) \\
\mathrm{O}_{2}+2 \mathrm{H}_{2} \mathrm{O}+4 e^{-} \rightarrow 4 \mathrm{OH}^{-}(\text {Cathodic reaction }) \\
\\
2 \mathrm{Fe}+2 \mathrm{H}_{2} \mathrm{O}+\mathrm{O}_{2} \\
\rightarrow 2 \mathrm{Fe}\left(\mathrm{OH}_{2}\right) \text { (sum of the reactions) }
\end{gathered}
$$


Equation (3) shows that iron and hydroxide ions react together to form solid iron hydroxide, also known as rust [6]. These complex iron oxides products can evolve according to the local environment. Depending on their level of oxidation and availability of moisture, the corrosion products will have specific volumes ranging from about two to six times that of the iron consumed. This will eventually lead to cracking of the concrete cover [7]. Currently there are no methods, to prevent corrosion of steel. Therefore, there is a need to know for how long a structure can serve both safely and efficiently. NACE international estimates that up to $35 \%$ of the cost of corrosion can be reduced by implementing corrosion mitigation methods like corrosion monitoring [3].

With the early detection of corrosion, appropriate action can be taken to maintain or even increase the service life of the structures. Repair and maintenance solutions such as the use of Fiber-reinforced polymer (FRP) [8] or impressed cathodic protection (CP) [9] can be initiated. Therefore, Structure Health Monitoring (SHM) systems for new infrastructure projects, are increasing internationally, as the awareness of structural integrity and safety, planning of repair works, and the associated costs have become areas of focus for the owners.

Existing SHM monitoring systems for RC structures typically rely on traditional wire-based electrochemical techniques, such as Linear Polarization Resistance (LPR), Open Circuit Potential (OCP) and Electrical Resistance (ER) technique [10].

The measurements from these sensors are mainly performed manually both in the handheld and embedded configurations. This is a labor intensive, time-consuming, and expensive task. Therefore, measurements are typically performed every second year in high-risk structures, such as an immersed tunnel. For adequate monitoring and mitigation of premature corrosion issues, many and frequent measurements are needed for proper data processing and interpretation. In accordance with an increased development of ultralow power Wireless Sensor Nodes (WSN) in recent years, utilizing such platforms will have tremendous benefits, such as real-time access for data. This makes it possible to centralize, process and analyze large numbers of data, collected from remotely placed structures. This can then be used to launch in-time repair and maintenance operations. One important challenge that must first be solved before WSN devices can be deployed in large quantities in harsh environments, is the powering of the sensor-nodes. Power grids are expensive to install, and the use of batteries have its shortcomings, such as limited capacity and lifetime and a subsequent need for replacement, which is an expensive task. Furthermore, batteries have environmental drawbacks since they contain toxic chemical contents, that must be disposed of at some point. In contrast, energy harvesting $(\mathrm{EH})$ can provide clean, reliable, and an in-situ power supply based on the conversion of ambient energy into electrical energy. By using $\mathrm{EH}$ hundreds to thousands of sensor nodes can simply be dispatched and forgotten.

\section{A. Energy harvesting in tunnels - A review}

From an EH perspective, a tunnel environment represents the worst-case scenario. The environment can be harsh and the ambient energies, such as solar irradiation, thermal, wind and kinetic energies are typically non-existing or limited inside the tunnel. The EH possibilities in tunnels have been investigated by few research groups. Wishcke et al. [11] have shown that it is possible to harvest enough vibrational energy for wireless transmission, from a piezoelectric vibration harvester placed on a train sleeper. They were able to harvest on average $395 \mu \mathrm{J}$ per train passing by. Unfortunately, they were not able to extract sufficient energy from the concrete wall or any other location in the tunnel, due to low vibrations. For corrosion sensors, which are embedded into the concrete wall, wires must then be drawn from the sleepers to the concrete wall. This will be a very costly task and pose a safety risk. Moser et al. [12] investigated the use of thermoelectric generators (TEG) to harvest electrical energy from a 1.2-degree temperature difference (Celsius) between a concrete wall and the ambient air in a tunnel. They were able to harvest $70 \mathrm{~mJ}$ per day, by designing the TEG harvester for that specific tunnel. This can be a viable solution, as the TEG can be in near proximity to the corrosion sensors. However, the energy harvested is quite low (over 24 hours), and it might not work in all environments.

A more omnipresent energy source, which is getting more attention, is the corrosion process (macro cell) itself since it is an energy release process. The harvesting of this energy form is not constrained by complex hardware circuitry since it does not need any energy conversion. This means that it has no mechanical parts, and it is near the corrosion sensor, making long lifetime of the monitoring system possible. Only few researchers have investigated the use of corrosion as a viable energy source. Ouellette et al. [13] have suggested using magnesium and carbon as the working electrodes in a half-cell reaction in concrete, in a marine environment. With their setup, they were able generate milliwatts of power, by making the electrodes large. Qiao et al. [14] have made use of smaller magnesium/zinc electrodes against a solid reference electrode instead. Their system was able to generate $63.5 \mu \mathrm{A} / \mathrm{cm}^{2}$, unfortunately they do not report any power output. Qiao et al. has further suggested in [15], the use of a carbon steel and graphite panel configuration to harvest micro energy. They were able to obtain hundreds of millivolts and hundreds to tens of microamps. Recently Zhang et al. [16] have designed a rechargeable concrete battery based on iron/zinc anodes and nickel-based (Ni) oxides as the cathodes. With this they were able to generate $7 \mathrm{Wh} / \mathrm{m}^{2}$.

Unfortunately, much of the research of corrosion harvesting are done under controlled laboratory setups, and no real-world results and implications are really discussed in detail. As stated by Quellette et al, one major concern when using this principle, is the corrosion byproducts. Magnesium and zinc's electrochemical potentials are more negative (active) than iron (steel) [17], and they are therefore more likely to corrode faster and create extra solid-by-products adding to the expansive stresses inside the concrete.

In this paper, the use of corrosion energy, for the first time ever (to the best of the authors knowledge), is investigated based on a real-world in-service immersed tunnel structure. Due to confidentiality reasons, the name and the location of the immersed tunnel cannot be disclosed.

Voltage and power measurements collected from the immersed tunnel are presented and discussed. A proof-of-concept demonstrator is built in the laboratory based on the collected measurements, to show the feasibility of harvesting energy for 
use in WSN to improve SHM. Furthermore, the total induced corrosion-rate of this system is calculated and discussed.

This paper is divided into the following sections. First, a background investigation on the energy harvesting possibilities in the immersed tunnels is made in section II. In section III, corrosion as an energy source is discussed based on the results from the immersed tunnel. In section IV, a laboratory experiment extracting energy through a power management system is analyzed and discussed, furthermore the total corrosion-rate is estimated. In section $\mathrm{V}$, the energy consumption of a simple long-range wireless sensor node is calculated. The paper ends with a discussion and conclusion in section VI and VIII, respectively.

\section{BACKGROUND: HARVESTING POSSIBILITIES}

The authors performed measurements in the immersed tunnel in November 2020. The tunnel has been in-service for many years. First, the possibilities of using thermoelectric generators (TEG) and vibrational harvester principles, as suggested by Moser [12] and Wishcke et al. [11] were investigated. Temperature measurements were performed at the concrete wall and the ambient air (in three different heights: the bottom, middle and top of the concrete wall). The measurements were performed close to one of the corrosion sensors boxes (see Fig.4.). The following readings were obtained (see Table 1).

TABLE 1

Temperature measurements performed in the immersed tunnel

\begin{tabular}{|l|l|l|l|} 
PLACEMENT & $\begin{array}{l}\text { WALL TEMP. } \\
\text { IN }^{\circ} \mathbf{C}\end{array}$ & $\begin{array}{l}\text { AMBIENT } \\
\text { TEMP. IN }^{\circ} \mathbf{C}\end{array}$ & $\begin{array}{l}\text { DIFFERENCE } \\
\mathbf{I N}^{\circ} \mathbf{C}\end{array}$ \\
\hline BOTTOM & 10.8 & 11 & 0.2 \\
\hline MIDDLE & 11.3 & 11 & 0.3 \\
\hline TOP & 10.9 & 11.1 & 0.2 \\
\hline
\end{tabular}

Here, it is seen that the temperature differences between the wall and ambient air are low, and not useful for TEG harvesting. Regarding vibrational harvester, no noticeable vibrations were observed on the concrete wall.

Harvesting energy from the artificial lighting was discarded due to the fact that the light in the service tube, where the sensor boxes are placed, are turned off, when not used. With harvesting energy from the lighting of the road and train tubes, the main concern is the dusty environment, which means that the photocells need regular cleaning, which is impractical and economically unfeasible. Therefore, the authors decided to continue with the corrosion principle.

\section{BACKGROUND: CONCRETE BATTERY FOR WSN}

The electrochemical corrosion reaction requires four electrical elements including anode, cathode, metallic and electrolytic conductor (ACME), as illustrated in Fig. 1. Here it is seen that at the anodic site, metal (steel) ions will be released to the solution (concrete), which results in mass loss. Electrons will flow from the anodic to the cathodic site (through the metal), meanwhile the iron ions react with water and oxygen (in marine environments) forming rust products, see equation (3).

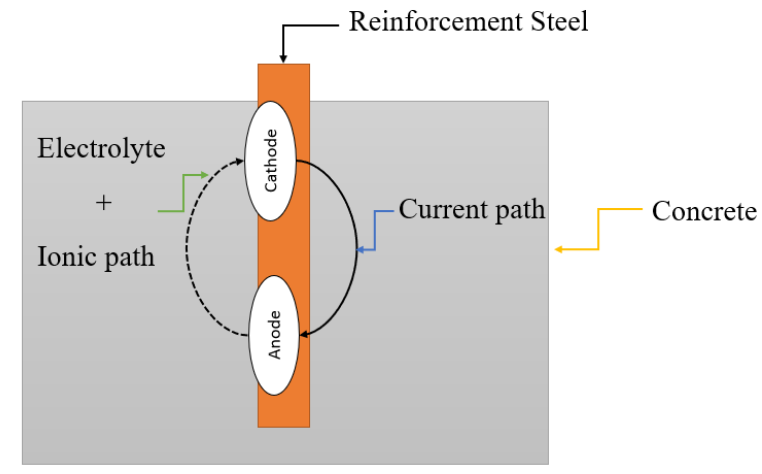

Fig. 1 Corrosion process in RC structures.

The rate at which ions (mass loss) are released to the concrete solution, is called the corrosion-rate, and are given in mass loss per year (typically $\mathrm{mm} /$ year) [10]. The locations of the anode and cathode are on an atomic level (microcell) and can interchange [18], and therefore cannot be identified. Therefore, to harvest this energy, a galvanic half-cell reaction is introduced [13] by having two dissimilar metal electrodes presented in the concrete, where one electrode acts as the anode (e.g., Steel) and the other one (more noble Metal B) as the cathode, as shown in Fig. 2. Due to the electromotive forces, potential difference between the metals occurs and electrons can flow - if an electrical connection is made between the electrodes. The principle functions as a battery, and this energy harvester will for the sake of simplicity - from now on be referred as a concrete battery.

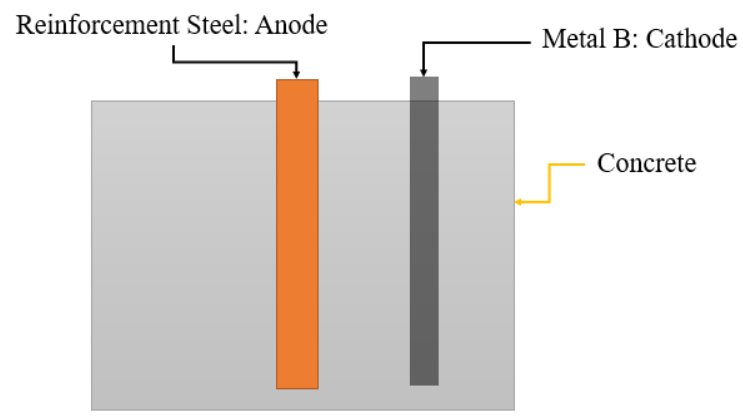

Fig. 2 A concrete battery; based on two dissimilar electrodes immersed in concrete.

The power output, which can be extracted from the concrete battery depends on many factors such as the reactivity, spacing, size of the metals and the concrete conductivity and environment [13]. The study here will not investigate these factors in depth, but instead use measurements performed in the immersed tunnel, to record the maximum voltage and power outputs that can be obtained. This will then be used to develop a simple proof-of-concept, self-sufficient WSN system in the laboratory.

\section{B. Sensors In the immersed Tunnel}

For corrosion monitoring, numerous electrochemical based sensors are embedded and dispatched through the immersed tunnel structure. The sensor system consists of the CorroWatch [19] and Embeddable Reference Electrode (ERE20) probe [20] 
developed by FORCE Technology (FT). In Fig. 3, a picture of the monitoring system can be seen before concrete casting.

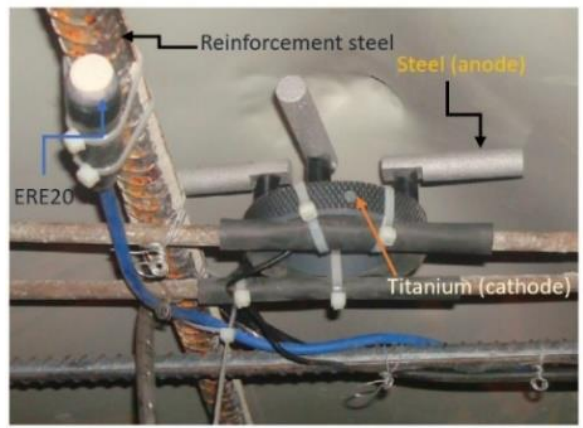

Fig. 3 The corrosion monitoring system in the immersed tunnel before concrete casting [19].

The CorroWatch sensor consists of four steel anodes (grey ones), in different defined heights (see [19] ), and a Mixed Metal Oxide (MMO) titanium mesh working as the cathode. The ERE20 probe is made of manganese dioxide, which is placed in a stainless-steel capsule along with cement electrolyte, making long life-time possible. For corrosion indication, voltage and (macro) current measurements are performed between the electrodes with a zero-Ohm ammeter [21]. Based on the measurements, the probability (based on ASTM [22]) of the corrosion can be deduced. All the measurements from the sensors (more than 900 measurement points) are currently done manually.

From the corrosion-box shown in Fig. 4, the probes to the sensors can be accessed, including the steel reinforcement itself.

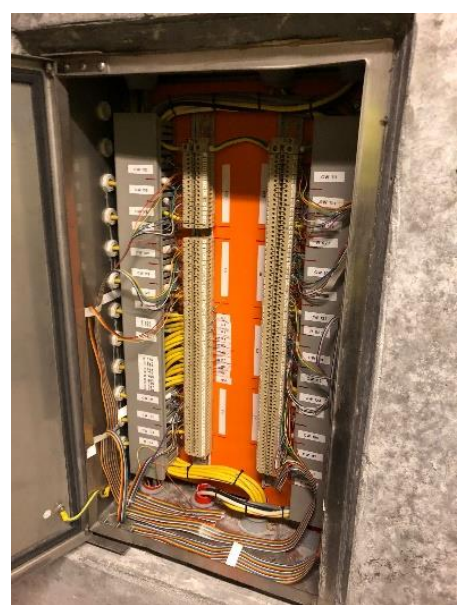

Fig. 4 The corrosion-box in the immersed tunnel, giving access to all the sensors, including the rebar.

\section{Voltage and power outputs of the concrete battery in the immersed tunnel (with cathodic protection system on)}

The sensors are based on galvanic half-cell reactions. This means that energy can be extracted and stored through a power management system for powering the WSN. The tunnel is built by many seqments. The sensors are dispatched through the whole segment surface, as seen in Fig.5, (only measured sensors are illustrated in the figure)

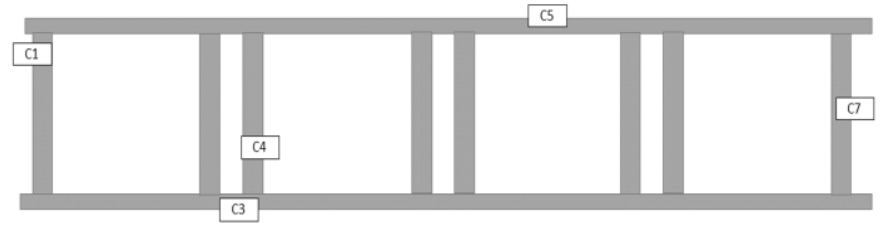

Fig. 5 Diagram of the placement of the sensors in the tunnel seqment.

The label $\mathrm{C}$ stands for CorroWatch (C), representing where those sensors are placed. Each CorroWatch has its own ERE20 probe in proximity, as seen in Fig. 3. The authors first measured the open circuit potential (with a regular multimeter) since this can indicate where the highest power output can be obtained. The impressed current cathodic protection (CP) system was running, while the measurements were performed. An illustration how the CP is configured and used is shown in Fig.6.; here it seen that the reinforcement steel is kept negative with respect to a sacrificial anode (e.g., titanium) placed in the seawater, through a power supply system.

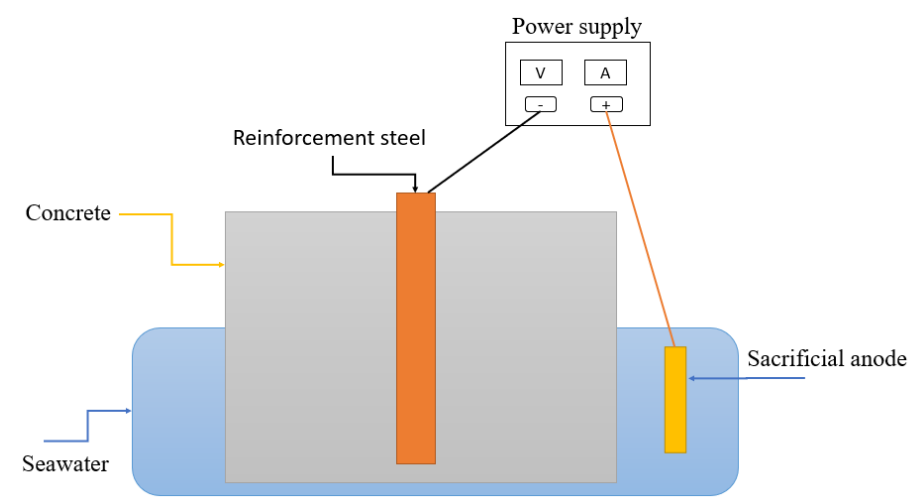

Fig. 6 Ilustration of the cathodic protection system setup

Potential measurements were made between the following electrodes

1. CorroWatch anodes, 1,2,3,4 vs. ERE20 as the cathode.

2. CorroWatch anode, 1,2,3,4 vs. (MMO) Titanium as the cathode

3. CorroWatch anode, $1,2,3,4$ vs. Reinforcement steel as the cathode

The measurements are done in five areas in the segment, $\mathrm{C} 1$, C3, C4, C5 and C7 (see Fig.5). For C5 and C3, only the CorroWatch anodes vs. the ERE20 probes were performed. The anodes and cathodes are put to the positive and negative (COM) terminal of the multimeter, respectively, therefore negative measurements are obtained c.f. corrosion measurement protocol. For energy harvesting only the potential difference, has an interest - therefore the negative sign is mostly ignored in this paper. In table 2, 4 and 5, it is seen that the potentials vary inside each separate location. For example, in location C1 (Table 2), the anodes vs. ERE20 probes, the range goes from $403 \mathrm{mV}$ in anode 1 to $975 \mathrm{mV}$ in anode 4. Similar large variations can also be seen with anodes vs. the Titanium/Reinforcement probes. Only location C4 (Table 4) has similar values in the potential measurements. 
TABLE 2

Potential measurements from location $C 1$.

\begin{tabular}{|l|l|l|l|}
\hline $\begin{array}{l}\text { CorroWatch } \\
\text { Anode: Vs. }\end{array}$ & $\begin{array}{l}\text { ERE20 } \\
{[\mathbf{m V}]}\end{array}$ & $\begin{array}{l}\text { Titanium } \\
{[\mathbf{m V}]}\end{array}$ & $\begin{array}{l}\text { Reinforcement } \\
\text { steel } \\
{[\mathbf{m V}]}\end{array}$ \\
\hline $\mathbf{1}$ & -403 & $\mathbf{- 5 7 8}$ & $\mathbf{- 4 7 0}$ \\
\hline $\mathbf{2}$ & -954 & -27 & -86 \\
\hline $\mathbf{3}$ & -852 & -130 & -60 \\
\hline $\mathbf{4}$ & $\mathbf{- 9 7 5}$ & -5 & -106 \\
\hline
\end{tabular}

TABLE 3

Potential measurements from location C4.

\begin{tabular}{|l|l|l|l|}
$\begin{array}{l}\text { CorroWatch } \\
\text { Anode: Vs. }\end{array}$ & $\begin{array}{l}\text { ERE20 } \\
{[\mathbf{m V}]}\end{array}$ & $\begin{array}{l}\text { Titanium } \\
{[\mathbf{m V}]}\end{array}$ & $\begin{array}{l}\text { Reinforcement } \\
\text { steel } \\
{[\mathbf{m V}]}\end{array}$ \\
\hline $\mathbf{1}$ & -174 & -55 & -31 \\
\hline $\mathbf{2}$ & -101 & -23 & -109 \\
\hline $\mathbf{3}$ & -116 & -7 & -93 \\
\hline $\mathbf{4}$ & -123 & -0 & -86 \\
\hline
\end{tabular}

TABLE 4

Potential measurements from location C7

\begin{tabular}{|l|l|l|l|}
\hline $\begin{array}{l}\text { CorroWatch } \\
\text { Anode: Vs. }\end{array}$ & $\begin{array}{l}\text { ERE20 } \\
{[\mathbf{m V}]}\end{array}$ & $\begin{array}{l}\text { Titanium } \\
{[\mathbf{m V}]}\end{array}$ & $\begin{array}{l}\text { Reinforcement } \\
\text { steel } \\
{[\mathbf{m V}]}\end{array}$ \\
\hline $\mathbf{1}$ & -589 & -323 & -274 \\
\hline $\mathbf{2}$ & -937 & -30 & -82 \\
\hline $\mathbf{3}$ & -315 & -598 & -546 \\
\hline $\mathbf{4}$ & -887 & -21 & -31 \\
\hline
\end{tabular}

TABLE 5

Potential measurements from:

\begin{tabular}{|c|c|c|c|}
\hline Location C3: & and & Location Cs & \\
\hline $\begin{array}{l}\text { CorroWatch } \\
\text { Anode: Vs. }\end{array}$ & $\begin{array}{l}\text { ERE20 } \\
{[\mathrm{mV}]}\end{array}$ & $\begin{array}{l}\text { CorroWatch } \\
\text { Anode: Vs }\end{array}$ & $\begin{array}{l}\text { ERE20 } \\
{[\mathrm{mV}]}\end{array}$ \\
\hline 1 & -402 & 1 & -502 \\
\hline 2 & -988 & 2 & -728 \\
\hline 3 & -866 & 3 & -354 \\
\hline 4 & -924 & 4 & -193 \\
\hline
\end{tabular}

The highest potentials can be achieved in the location $\mathrm{C} 1$ (table 1), C7 (table 4) and C3 (table 5). These sensors are the ones closest to the seawater. The lowest potentials are at $\mathrm{C} 4$ (table 3 ), which is in the middle of the segment, and thereby well protected from the seawater. The highest open circuit potential can be achieved with the anodes vs. ERE20 probes. The highest measured potential difference is $988 \mathrm{mV}$ between anode 2 vs. ERE20 in location C3 (Table 5). A large potential difference (more negative potential) does not necessarily mean a severe corrosion condition. When concrete is water saturated - it reduces the access of oxygen to the steel surface. This depletion of oxygen results in a corrosion potential drop to very negative values [6]. For more adequate interpretation and assessment, the chloride ingress and $\mathrm{pH}$ level should be known. This paper is not trying to assess and evaluate the corrosion situation in the tunnel - and therefore no further discussions will be made of this topic.

Only power measurements from location C1 (Table 2) were taken, which has the next highest potentials. According to [13] this concrete battery setup has both capacitive and resistive electrical components, but it is mostly dominated by its resistive behavior and can therefore be modelled as a DC source. The power output can be described as:

$$
P_{L}=V_{S}^{2} \frac{R_{L}}{\left(R_{S}+R_{L}\right)^{2}}
$$

Where $V_{S}$ and $R_{S}$ are the equivalent source voltage and the concrete battery resistance, respectively. $\mathrm{R}_{\mathrm{L}}$ is the external application load resistance between the electrodes. The maximum power that can be found by solving the following equation:

$$
\frac{d P_{L}}{d R_{L}}=0
$$

This holds true when $\mathrm{R}_{\mathrm{L}}=\mathrm{R}_{\mathrm{S}}$. Therefore, for the measurements, a resistive sweep from $1 \mathrm{k} \Omega$ to $100 \mathrm{k} \Omega$ with a potentiometer was performed to find the maximum power output. The voltage between the electrodes (anodes vs. cathodes) were measured with 30 seconds of measurement time to ensure stable readings. In the figures below, the voltage (blue) and power (red) outputs are plotted for different probe configurations. As observed in the figures, most power can be extracted from the CorroWatch anode 4 vs. ERE20 probe, with a maximum output power of 12.4 $\mu \mathrm{W}$ at a voltage of $\mathbf{4 9 8} \mathbf{~ m V}$ (see Fig. 7.), while the CorroWatch anode 1 vs. steel reinforcement can deliver $\mathbf{4 . 4 8 5}$ $\boldsymbol{\mu W}$ of power output (see Fig.8.), at a voltage of $\mathbf{1 1 6} \mathbf{~ m V}$. CorroWatch anode 1 vs. Titantium can deliver approximately the same (Fig. 9.).

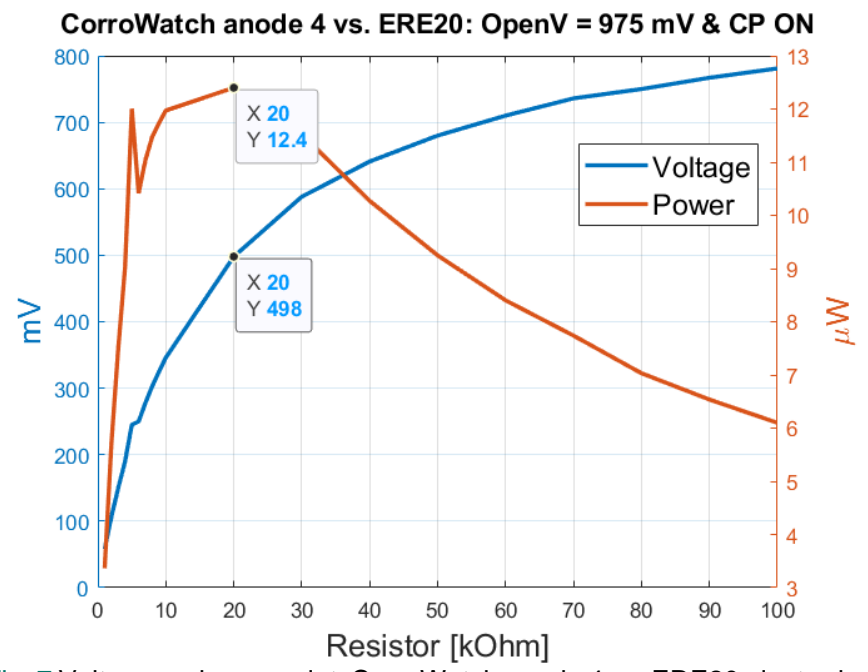

Fig. 7 Voltage and power plot: CorroWatch anode 4 vs. ERE20 electrode with the cathodic protection system on.

In a real-world application, dedicated electrodes should be embedded only for energy-harvesting purposes, otherwise the electrodes working as sensors might be affected leading to wrong readings. 


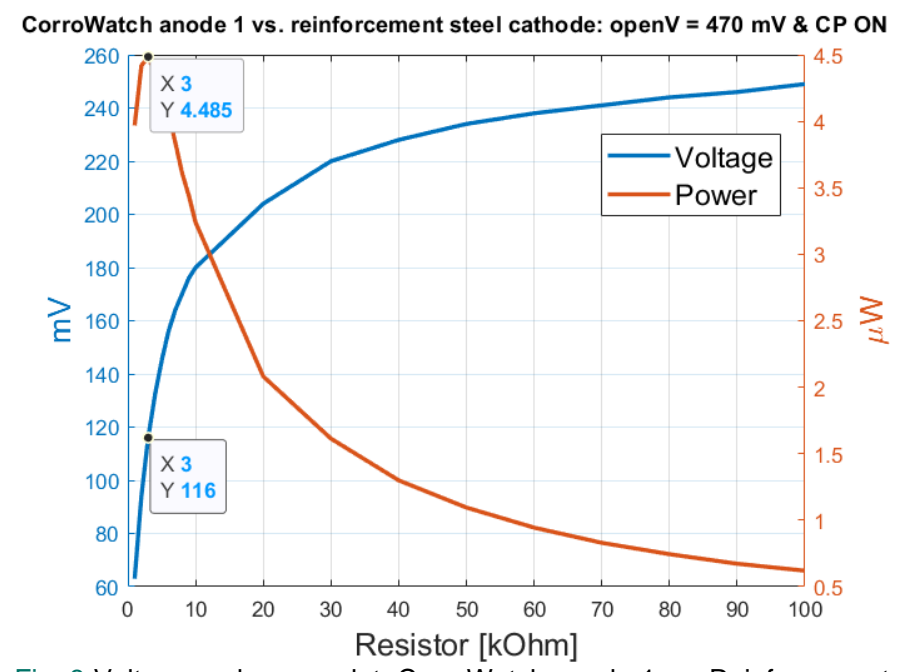

Fig. 8 Voltage and power plot: CorroWatch anode 1 vs. Reinforcement steel electrode with the cathodic protection system on.

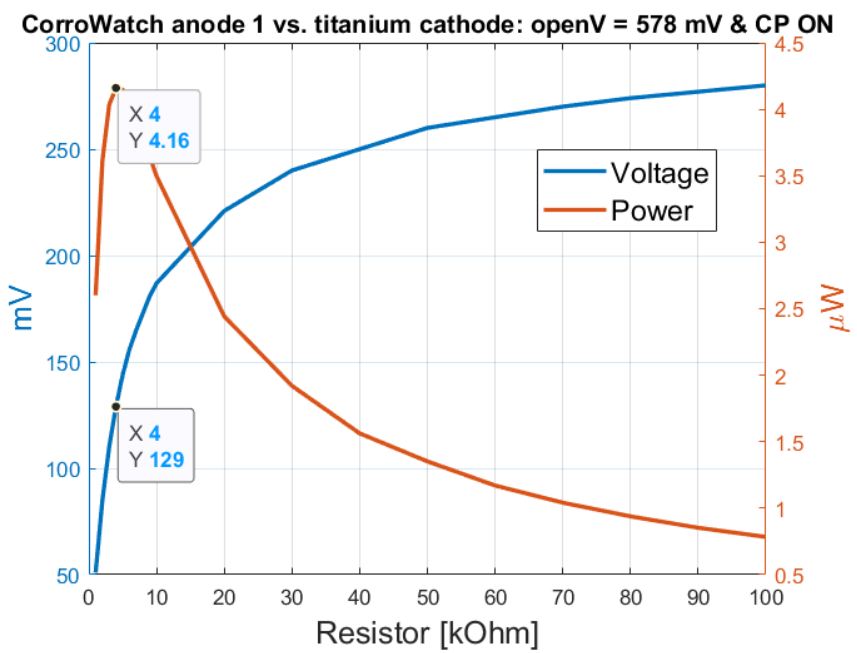

Fig. 9 Voltage and power plot: CorroWatch anode 1 vs. Titanium electrode with the cathodic protection system on.

\section{Voltage and Power outputs of the concrete battery in the tunnel (cathodic protection system off)}

To investigate how the $\mathrm{CP}$ system affects the measurements, it was turn off and the same measurements for $\mathrm{C} 1$ was recorded 6 days later. The data (see Table 6) shows a drop in some of the potentials, and an increase in others. For example, anode 1 vs. ERE20, has increased from $403 \mathrm{mV}$ to $522 \mathrm{mV}$, while anode 4 vs. ERE20 has decreased from $945 \mathrm{mV}$ to $870 \mathrm{mV}$. TABLE 6

Potential measurements from location $C 1$, when $C P$ system is off.

\begin{tabular}{|l|l|l|l|}
\hline $\begin{array}{l}\text { CorroWatch } \\
\text { Anode: } \text { Vs. }\end{array}$ & $\begin{array}{l}\text { ERE20 } \\
{[\mathbf{m V}]}\end{array}$ & $\begin{array}{l}\text { Titanium } \\
{[\mathbf{m V}]}\end{array}$ & $\begin{array}{l}\text { Reinforcement } \\
\text { steel: }[\mathbf{m V}]\end{array}$ \\
\hline $\mathbf{1}$ & -522 & $\mathbf{- 3 9 7}$ & $\mathbf{- 2 0 1}$ \\
\hline $\mathbf{2}$ & -867 & -52 & -143 \\
\hline $\mathbf{3}$ & -761 & -159 & -37 \\
\hline $\mathbf{4}$ & $\mathbf{- 8 7 0}$ & -49 & -147 \\
\hline
\end{tabular}

Regarding the power output, a decrease from $12.4 \mu \mathrm{W}$ to $\mathbf{9 . 1 8}$ $\boldsymbol{\mu W}$ ( at a voltage of $\mathbf{3 0 3} \mathbf{~ m V}$, see Fig.10.), is observed with the anode 4 vs. ERE20 cathode. In anode 1 vs. reinforcement steel cathode, the power drop goes from $4.48 \mu \mathrm{W}$ to $\mathbf{1} \boldsymbol{\mu W}$ (with voltage of $\mathbf{4 5 ~ m V}$, see Fig.11.). In anode 1 vs. titanium cathode, the power drop is from $4.12 \mu \mathrm{W}$ to $\mathbf{2 . 7 5} \boldsymbol{\mu W}$ (at a voltage of $105 \mathrm{mV}$, see Fig.12.).

When the $\mathrm{CP}$ was turned on again, a quick potential increase is observed. These results therefore indicate that the large current (up to $35 \mathrm{~A}$ ) from the $\mathrm{CP}$ system has an impact on the whole concrete structure and is not confined only to the steel reinforcement.

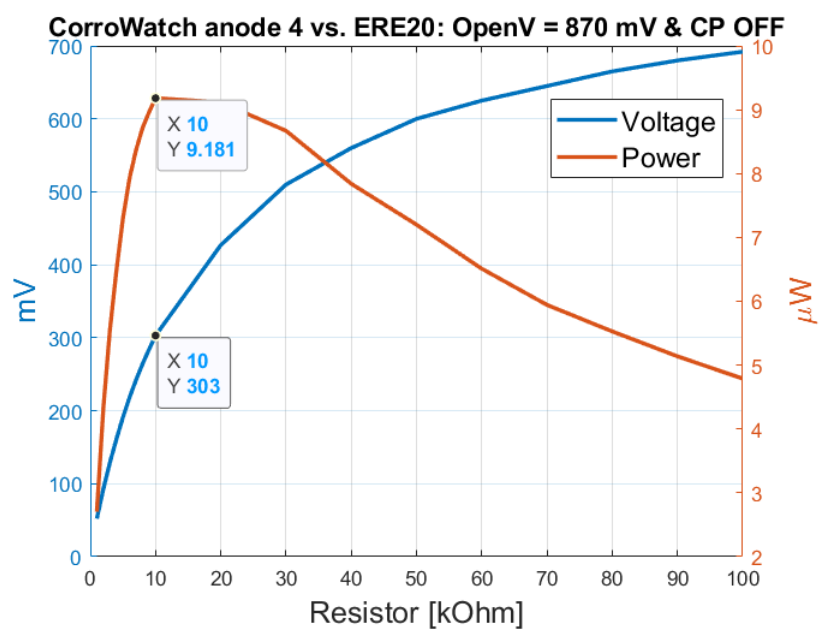

Fig. 10 Voltage and power plot: CorroWatch anode 4 vs. ERE20 electrode with the cathodic protection system off.

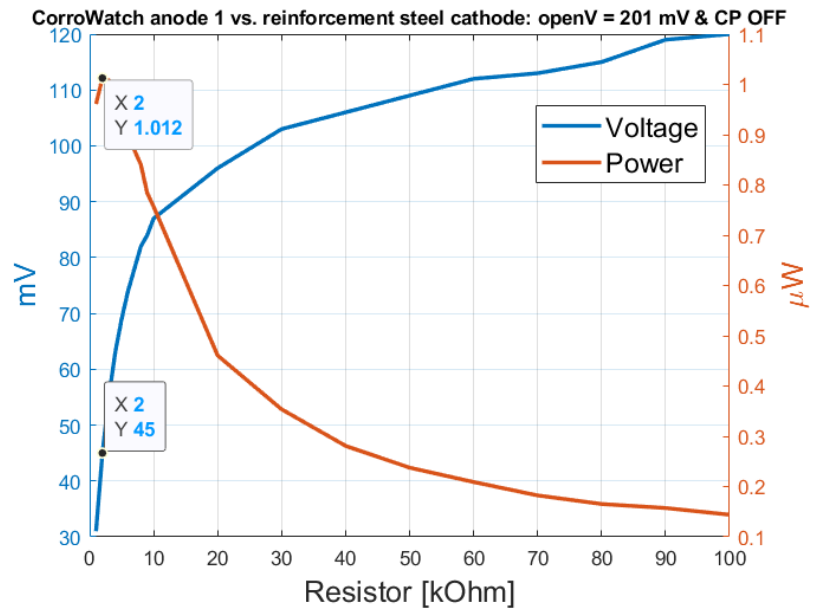

Fig. 11 Voltage and power plot: CorroWatch anode $1 \mathrm{vs.} \mathrm{Steel}$ reinforcement with the cathodic protection system off.

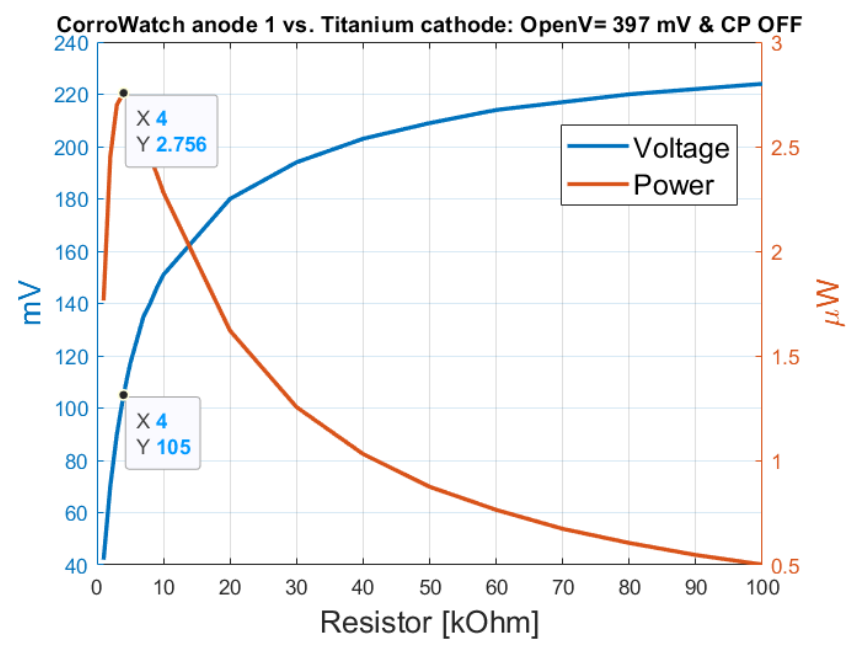

Fig. 12 Voltage and power plot: CorroWatch anode 1 vs. Titanium electrode with the cathodic protection system off. 
This time the authors also performed measurement directly between the steel reinforcement (working as an anode) itself and the ERE20 (cathode) probe in location $\mathrm{C} 1$.

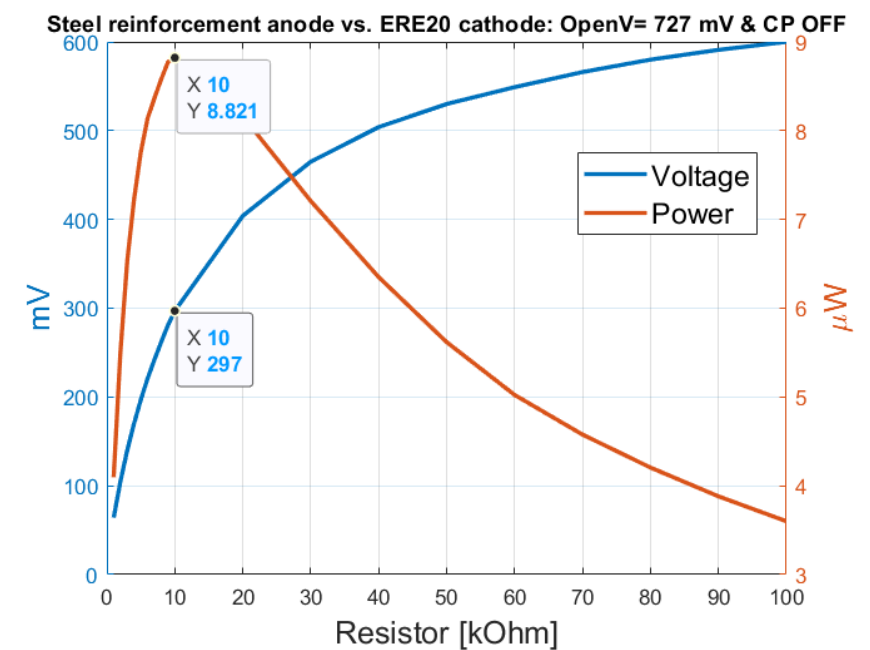

Fig. 13 Voltage and power plot: Steel reinforcement anode vs. ERE20 electrode with the cathodic protection system off.

Here it is seen that $8.82 \mu \mathrm{W}$ (at a voltage of $\mathbf{2 9 7} \mathbf{m V}$, see Fig.13.), can be harvested directly from the steel reinforcement, when the CP is off. This is (assumed) the second highest output power that can be harvested after the anode 4 vs. ERE20 probe.

\section{POWER MANAGEMENT SYSTEM}

The measured voltages and power outputs are too low to drive a wireless sensor node. Therefore, the extracted energy shall be stored over some period. Extracting and storing the energy is the task of a power management system (PM). It typically consists of a DC/DC boost converter and a storage element, e.g., supercapacitor (Super cap). An illustration of the power management setup with the concrete battery harvester is shown in Fig. 14.

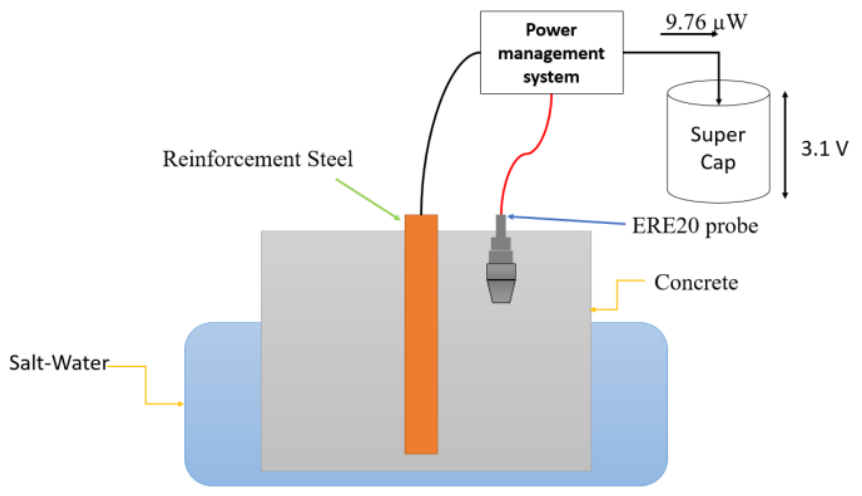

Fig. 14 Illustration of a concrete battery attached to a powermanagement system (wet concrete setup).

There are few commercially available PM systems with ultralow-power operations and useful for this setup. Qiao et al. [15] used the BQ25504 ultra low-power boost converter from Texas instrument - it needs minimum a cold-start voltage of $600 \mathrm{mV}$ and input power of $\mathbf{1 5} \boldsymbol{\mu W}$ [23]. Since the concrete battery can deliver an (assumed) maximum power of $\mathbf{1 2 . 4} \boldsymbol{\mu W}$, a lower power PM system is needed.

After conducting a tradeoff analysis, the choice fell on the EM8500 power management chip from EM Microelectronic
[24]. The chip is claimed to have an efficiency of $80 \%$ ( maximum point tracking with solar cell) with the following important features:

\section{Cold start:}

1. Cold-start minimum harvester voltage: $V D D \_H R V \geq$ $300 \mathrm{mV}$

2. Cold-start minimum harvester power: $P_{-} H R V \geq$ $3 \mu W$

\section{Cold start end at $1.3 \mathrm{~V}$ (typ):}

1. Operation mode minimum voltage: $V D D \_H R V \geq$ $100 \mathrm{mV}$

2. Operation mode minimum power: : $P_{-} H R V \geq 1 \mu W$

The input (harvester) voltage range to the $\mathrm{PM}$ is from $0.1 \mathrm{~V}$ to $1.8 \mathrm{~V}$. The storage element can be configured to charge up to different voltages such as $3.1 \mathrm{~V}$. The PM chip should therefore be able to work with the voltage and power outputs of the CorroWatch/steel reinforcement anode vs. ERE20 cathode configurations in the cold-start phase. After the cold start phase CorroWatch anode vs. the titanium\reinforcement steel cathode can also be fully utilized for energy extraction (with $\mathrm{CP}$ on case).

\section{A. Laboratory experiments}

For further experiments, tests were performed in the laboratory, by embedding the same electrodes as in the immersed tunnel, inside small concrete samples (cube size - length $=14 \mathrm{~cm}$, diameter $=11 \mathrm{~cm}$, and rebar length and diameter of $15 \mathrm{~cm}$ and $0.8 \mathrm{~cm}$ respectively see Fig. 15.). To avoid the effect of the curing process, voltage and power measurements were performed 1 month after the concrete samples were made. From Fig. 16 and 17, in the newly made concrete samples, which are placed under dry condition, it is seen that the voltage between the steel anodes and with both ERE20 and the titanium cathode, it is only in the range of tens of $\mathrm{mV}$, and the power-outputs are in the nanoscale range. These power levels are not useful for energy harvesting.

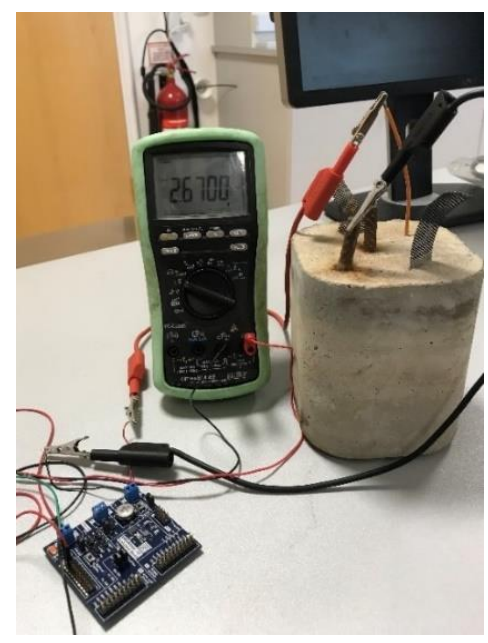

Fig. 15 Picture of the concrete sample, charging up a 544-mF supercapacitor up to $3.1 \mathrm{~V}$. 


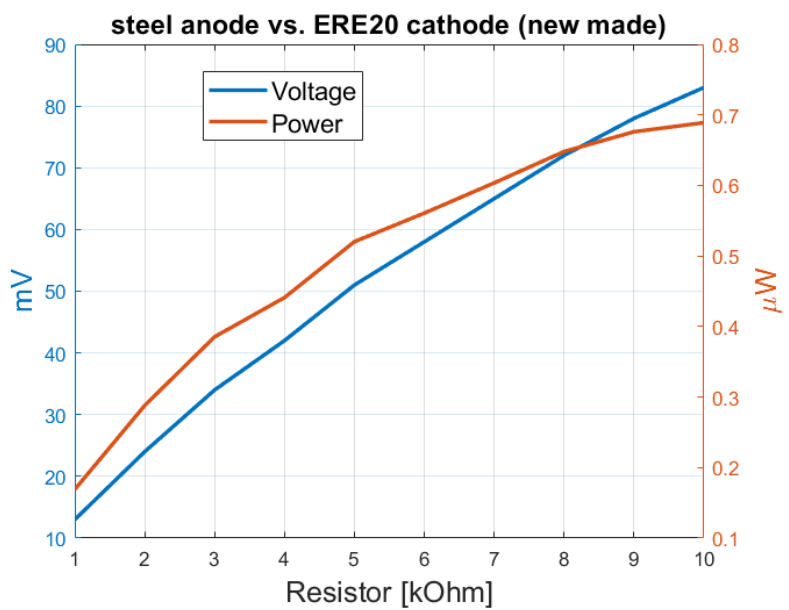

Fig. 16 Voltage and power measurements in a fresh made concrete using steel anode vs. ERE20 probe.

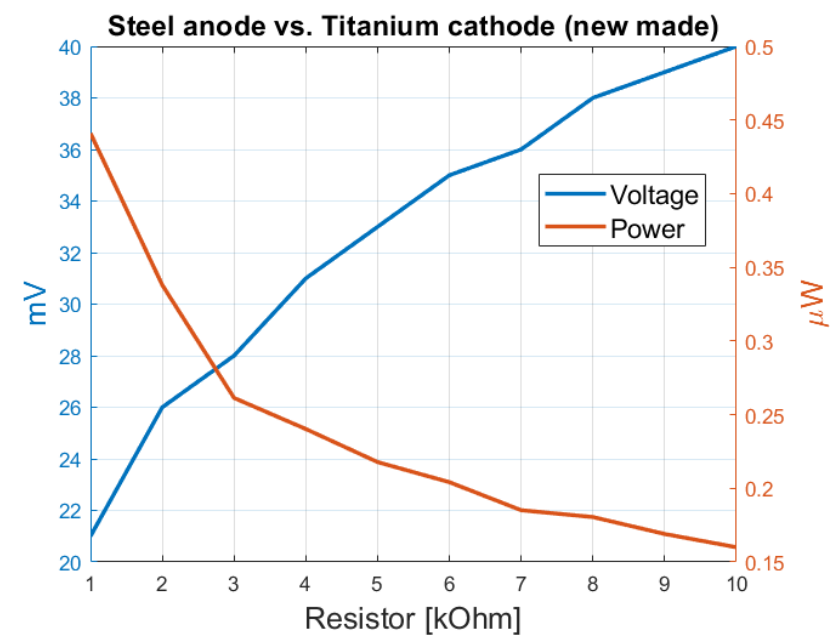

Fig. 17 Voltage and power measurements in a fresh made concrete using steel anode vs. titanium probe.

To simulate the power outputs (between $12 \mu \mathrm{W}$ and $1 \mu \mathrm{W}$ ) from the immersed tunnel, a concrete sample is immersed into saltwater and afterwards put under dry conditions until $7 \mu \mathrm{W}$ was obtained. The storage element that the PM system is charging is a $544-\mathrm{mF}$ supercapacitor. The PM system stopped charging the capacitor, due to insufficient input power, after 14 days. The final voltage was $2.6 \mathrm{~V}$, equivalent to $1.8 \mathrm{~J}$. From Fig. 18, it is seen that the power level drops from $\mathbf{7} \boldsymbol{\mu W}$ (start power) to $\mathbf{2 . 3}$ $\boldsymbol{\mu} \mathbf{W}$ (stop power), if looking at the same resistor value (y-axis). This seems to be the lower power input limit with the current setup.

Seawater content (salt, moisture and water composition) is important for the sustainability and performance of the concrete battery [16], as also seen from the potential measurements in C4 (dry area) from the tunnel in section III. Therefore, in a realworld immersed tunnel setup, it would be expected, that the power output would be higher and more constant, at the wet locations. To investigate this, the same concrete sample was partially immersed into salt-water (see Fig. 14) in a bucket. Here it is seen (see Fig.19.) that the power only drops with $\mathbf{0 . 9}$ $\boldsymbol{\mu W}$ even after harvesting for 40-days (the salt-water in the bucket did gradually evaporate).

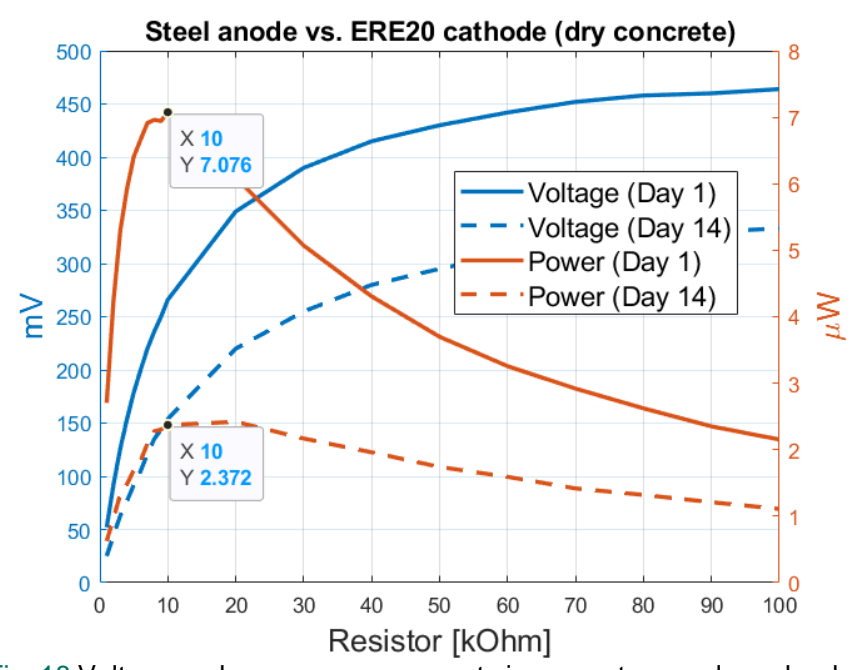

Fig. 18 Voltage and power measurements in concrete sample under dry conditions.

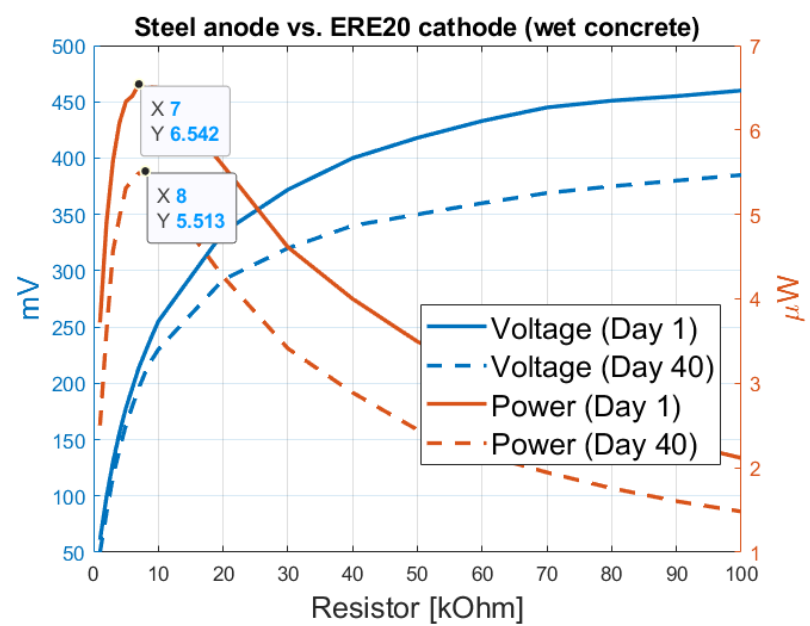

Fig. 19 Voltage and power measurements when immersing the concrete into saltwater to simulate marine environment.

In a real-world seawater environment, it is expected that the drop would be even lower - due to the constant water content and no evaporation.

\section{B. Corrosion rate of the concrete battery}

The chloride induced corrosion rate in marine environment ranges typically from $9 \mu \mathrm{m}$ to $122 \mu \mathrm{m}$ per year [6]. Generally, the relationship between the severity and corrosion-rate can be defined as shown in Table 7:

$$
\text { TABLE } 7
$$

Relationship between severity and corrosion-rate [25].

\begin{tabular}{|l|l|}
\hline Severity: & Corrosion rate $(\mu \mathrm{m} /$ year $)$ \\
\hline Low corrosion rate: & $2-4$ \\
\hline Low to moderate corrosion: & $5-9$ \\
\hline Moderate to high corrosion: & $10-49$ \\
\hline Very high corrosion: & $50-99$ \\
\hline
\end{tabular}

To calculate an approximated theoretical galvanic corrosion rate induced by the concrete battery, Faraday's law can be used, since the flux of ions and electrons can be taken as a measure of the corrosion-rate. This is also called the penetration depth, and it is described as: 


$$
p_{c o r r}=\frac{W_{F e} \times I_{c o r r}}{Z_{F e} \times F \times G_{F e}} \times 31.56 \cdot 10^{6} s
$$

Where, $\mathrm{P}_{\text {corr }}=$ corrosion penetration rate, $[\mathrm{mm} / \mathrm{year}], \mathrm{W}_{\mathrm{Fe}}=$ atomic weight for iron $\approx 56 \mathrm{~g} / \mathrm{mole}, \mathrm{I}_{\text {corr }}=$ corrosion current density $\left[\mathrm{A} / \mathrm{m}^{2}\right], \mathrm{Z}_{\mathrm{Fe}}=$ valency of iron molecule, $\mathrm{Z}_{\mathrm{Fe}}=2, \mathrm{~F}=$ faraday constant, $\mathrm{F} \approx 96500 \mathrm{C} /$ mole, $\mathrm{G}_{\mathrm{Fe}}=$ density of iron $\approx$ $7874 \mathrm{~kg} / \mathrm{m}^{3} .31 .56 \cdot 10^{6} \mathrm{~s}$ are years in seconds.

The maximum power, which can be extracted from the immersed tunnel, is between CorroWatch anode 4 vs. ERE20 probe. It is the anodes, that undergoes oxidation (losses mass). The anode has a length of $60 \mathrm{~mm}$ and a diameter of $12 \mathrm{~mm}$. To obtain the corrosion rate, the surface area of the anode is calculated as:

$$
\text { Surface Area }=2 \pi r^{2}+h(2 \pi r)
$$

This gives a surface area of $24.8 \mathrm{~cm}^{2}$. The maximum power output which can be extracted from the concrete battery in the tunnel was $12.4 \mu \mathrm{W}$. This is equivalent to a (galvanic) corrosion current of $24 \mu \mathrm{A}$ per $24.8 \mathrm{~cm}^{2}$. The current density is therefore:

$$
\begin{aligned}
\text { Current density } & =\frac{24 \mu \mathrm{A}}{0.00248 \mathrm{~m}^{2}} \\
& \approx 9.68 \frac{\mathrm{mA}}{\mathrm{m}^{2}}
\end{aligned}
$$

From equation (8) the total (galvanic) corrosion rate can be calculated by using equation (6). The total (galvanic) corrosion rate per year will be $11.3 \mu \mathrm{m} /$ year, if the concrete battery is under constant usage. This can be considered as moderate high corrosion rate. If the harvesting of the concrete battery is done in 10 days per month (120 days/year; as needed for powering a WSN) and then the electrical connection (between anode and cathode) is broken, - the induced corrosion-rate will then be reduced to only $3.7 \mu \mathrm{m} /$ year, this is a low corrosion rate. Further if the harvesting is done 10 days - every second month, the corrosion rate is further reduced to $1.8 \mu \mathrm{m} /$ year.

\section{WIRELESS SENSOR NODE BASED ON LORA:}

The wireless transmission is typically the most powerconsuming operation of a sensor-node, and the harvested energy should be sufficient to meet this power requirement. An illustration of the WSN system setup similar to [26] can be seen in Fig. 20. In this proof-of-concept demonstration, for the wireless communication, the WiMod [27] radio module iM282A is used. The WiMod module operates in the $2.4 \mathrm{GHz}$ frequency band using Semtech's LoRa ${ }^{\mathrm{TM}}$ modulation technology, has low power consumption and long transmission range. For the test setup, the default configuration is used (bandwidth of $200 \mathrm{kHz}$ and spreading factor of 11). The module is used in a peer-to-peer configuration.

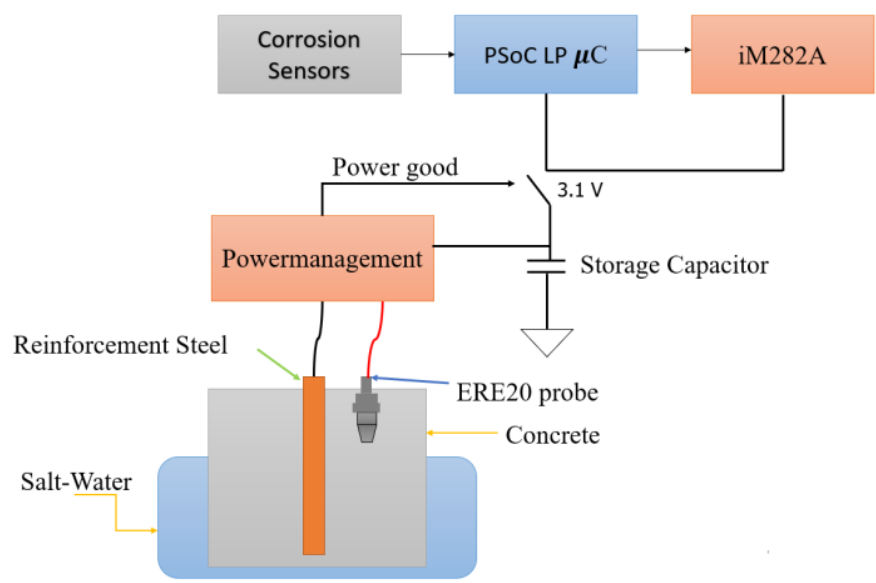

Fig. 20 System setup for the self-powered wireless sensor-node.

For transmitting 2 bytes, through the wireless module controlled by a PSoC5 LP, the current consumption is measured as shown in Fig. 21.

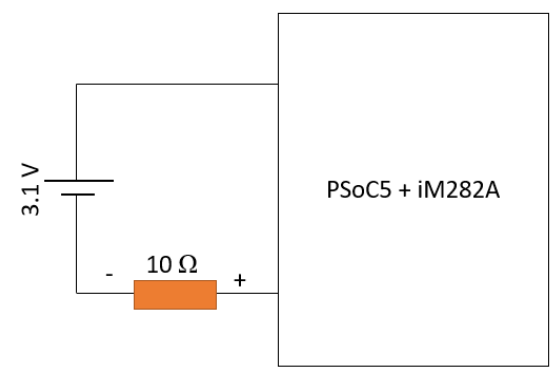

Fig. 21 Current consumption measurement of the WiMod and PSoC LP.

$$
V_{R 1}=\frac{522 \mathrm{mV}}{10 \Omega}=52.2 \mathrm{~mA}
$$

From equation (9), it is seen that the maximum current consumption for wireless transmissions is $52.2 \mathrm{~mA}$. To calculate the energy usage, the transmission duration is measured as seen in Fig. 22.

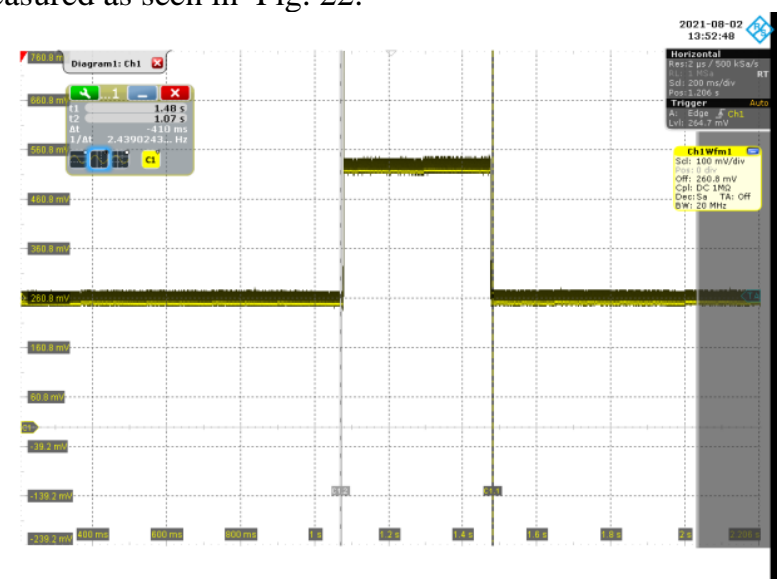

Fig. 22 Transmission time measurement of the system.

The total transmission time for sending 2 bytes is measured to be 412 milliseconds. The energy consumption is, therefore:

$$
\begin{aligned}
E_{\text {Tranmission }}= & 3.1 \mathrm{~V} \times 52.2 \mathrm{~mA} \\
& \times 410 \mathrm{~ms}=66.35 \mathrm{~mJ}
\end{aligned}
$$


For sampling the voltage from the corrosion sensors $(1 \mathrm{mV}$ to $1 \mathrm{V)} 4$ bytes are needed, so $66.35 \mathrm{~mJ}$ is multiplied with 2 .

To calculate the needed storage capacitor, the minimum supply voltage of the device (iM282A + PSoC5 LP) was measured to be $2.4 \mathrm{~V}$.

$$
\begin{gathered}
C_{\text {Storage }}=\frac{133 \mathrm{~mJ}}{0.5 \times(3.1 \mathrm{~V}-2.4 \mathrm{~V})^{2}} \\
=536 \mathrm{mF}
\end{gathered}
$$

The used storage supercapacitor is $544 \mathrm{mF}$ therefore, the total stored energy is.

$$
\begin{aligned}
C_{\text {Storage }}=0.5 \times & (3.1 \mathrm{~V})^{2} \times 544 \mathrm{mF} \\
& =2.614 \mathrm{~J}
\end{aligned}
$$

Transmitting corrosion potential measurements once or every second month is a sufficient frequency for proper data interpretation. If the power delivery $(12 \mu \mathrm{W})$ of the concrete battery is assumed constant and the efficiency of system is set to $70 \%$. Charging the supercapacitor to $3.1 \mathrm{~V}$ can roughly be calculated as,

$$
t_{\text {Charge }}=\frac{2.614 J}{12 \mu W \times 0.70} \approx 3 \text { days }
$$

It will take 3 days to charge the supercapacitor to $3.1 \mathrm{~V}$ - but due to the leakage current of the supercapacitor, a more realistic number is 6 days for a full charge. 6 days is more than a sufficient transmission-rate. With the dry concrete sample with an initial power of $\mathbf{1 3} \boldsymbol{\mu W}$, it took approximately 9 days to charge the $544-\mathrm{mF}$ capacitor from $100 \mathrm{mV}$ to $3.1 \mathrm{~V}$. The recharging can then start from $2.4 \mathrm{~V}$ up to the needed $3.1 \mathrm{~V}$, reducing the next charging time. In the corrosion-rate calculations harvesting under dry condition are used, and 10 days are therefore seen as the worst-case scenario time duration for the harvesting period.

Fig. 23 (a) shows the received data packet from the WSN, using power from the concrete battery. It contains the voltage (375 $\mathrm{mV}$ ) from the corrosion sensor, (b) shows the same measurement with a multimeter - showing $375 \mathrm{mV}$.

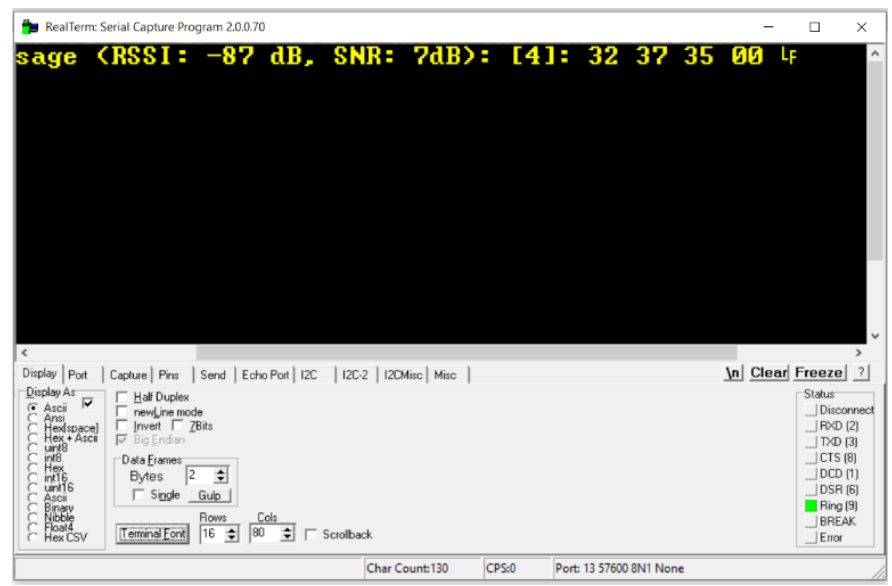

(a)

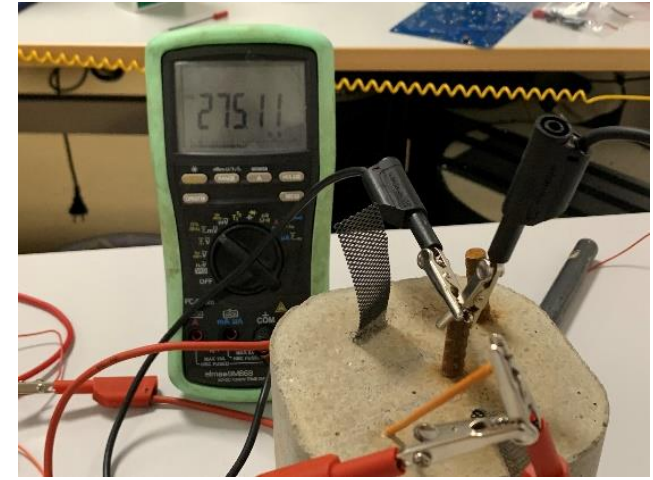

(b)

Fig. 23: Potential measurements from corrosion sensors - showing (a) from the self-sufficient WSN - shown on the base-station serial terminal ( $375 \mathrm{mV}$ (ASCII signs) and (b) measurement from a multimeter showing $375 \mathrm{mV})$.

For data visualization, an online cloud platform (Microsoft Azure) was made (see Fig.24) collecting and plotting the corrosion data from immersed tunnel. Here the engineer/inspector can remotely follow the corrosion data from the sensors.

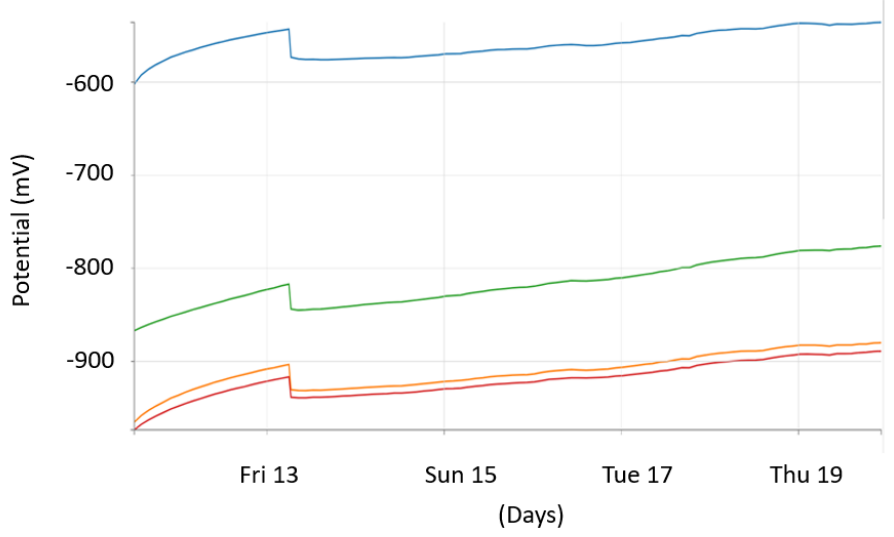

Fig. 24: Corrosion data sent to the cloud (Microsoft Azure webservice) and plotted in a graph.

\section{DISCUSSION:}

Generally, it is well-known that the construction industry is conservative regarding adaptation of new technologies. This is understandable since the liability and stakes associated with construction work are very high, regarding safety and cost, making any owner and engineer cautious about taking any risk. In the literature, materials such as magnesium and zinc are often suggested as possible electrodes but embedding many of these in reinforced concrete may lead to an increase in the corrosion byproducts, accelerating the deterioration process.

Therefore, this study used existing concepts with a long trackrecord to show that sufficient energy to drive a WSN for long term SHM is possible and can be done safely. The calculated corrosion-rate induced - for a data transmission per month, is very low. If a structure is already experiencing even small corrosion issues, the negative contribution of utilizing this system will be insignificant.

The cathodic protection system is a factor that seems to change the potential dynamics - at some locations the voltage decreases and at other locations the voltage increases when the $\mathrm{CP}$ is 
turned off. More investigations must therefore be performed to get a clearer picture of its influence. Some authors like [28] and [29] have suggested using the CP as a direct energy source itself. Since the CP system is connected directly to the reinforcement steel, the most impact should be seen at the CorroWatch anode 1 vs. steel reinforcement cathode. Here a power drop from $4.16 \mu \mathrm{W}$ to $1 \mu \mathrm{W}$, can be observed, when the $\mathrm{CP}$ is turned off. For steel Reinforcement anode vs. ERE20 cathode (see Fig.13.), data were unfortunately not recorded for when the $\mathrm{CP}$ was on. But looking at previous data collected from 2018, in a different section, with the CP on, the open circuit potential was measured to be $875 \mathbf{~ m V}$ (steel reinforcement anode vs. ERE20 cathode), and from the current data, the open circuit potential is $\mathbf{7 2 7} \mathbf{~ m V}$ with the CP system off. This indicates that the CP system will not give significant more energy to extract, in the configurations used in this study. If the steel reinforcement and ERE20 probe are used as the anode and cathode, the use of the CP will protect the steel from mass-loss, since the 'lost' electrons are replaced (depending on the efficiency of the CP system) .

The laboratory test on the reinforced concrete samples shows that in new dry concrete samples no useful energy can be extracted, similar observations can be seen from the tunnel in location C4 (dry area). For immersed tunnels, the required time for harvesting enough energy depends on many external factors, e.g., oxygen, salt, moisture and water composition content in the concrete.

In a small investigation, a concrete sample with embedded reinforcement steel (20 cm long and $16 \mathrm{~mm}$ in diameter) and a ERE20 probe was made (see Fig.25.). The concrete cover thickness was $50 \mathrm{~mm}$. Only the top surface of the reinforcement steel is exposed. The concrete was first placed inside, where the power measurements were performed, after that the concrete was placed outside (in November/December month in Aarhus,DK).

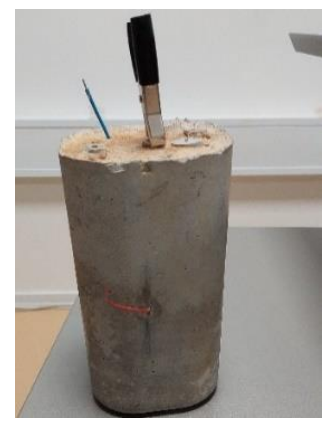

Fig. 25 Reinforced Concrete sample with steel anode and ERE20 probe and embedded.

From Fig.26, it is seen how the power levels increase the longer the concrete is exposed to the out-door conditions. When the concrete sample was placed inside only $0.42 \mu \mathrm{W}(15 / 11)$ could be harvested. The first 12 days the power only increased with a small amount. From $27 / 11$ to $4 / 12$, it took a jump in the power level. During that week, it was snowing and raining heavily in the city. This indicates, that when the concrete is exposed to 'harsh' climate - more energy is generated.

Fig 27. Shows the potential measurement between the steel reinforcement vs. ERE20 probe, when inside and when placed outside for that whole month. For proper energy harvesting, a minimum of 3-5 $\boldsymbol{\mu W}$ is needed.

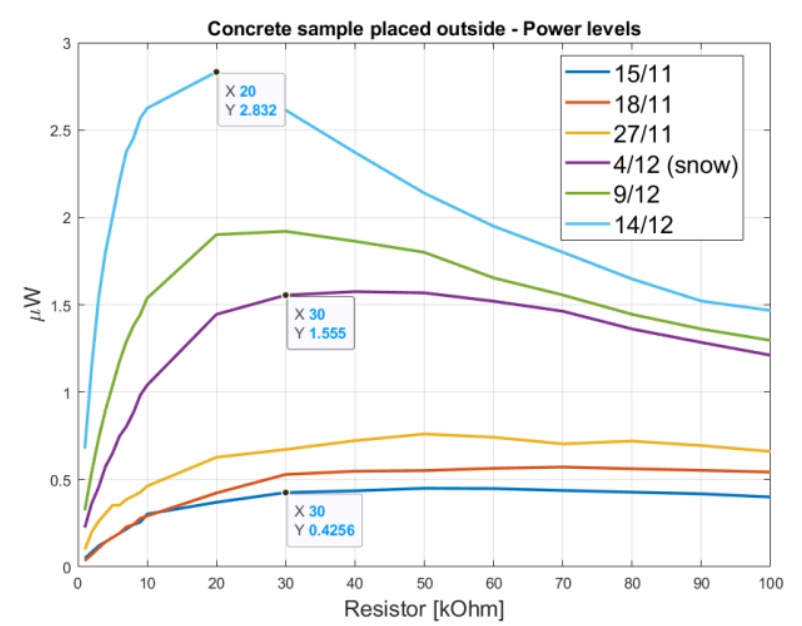

Fig. 26 Power measurements of the concrete sample over a period of 1 month.

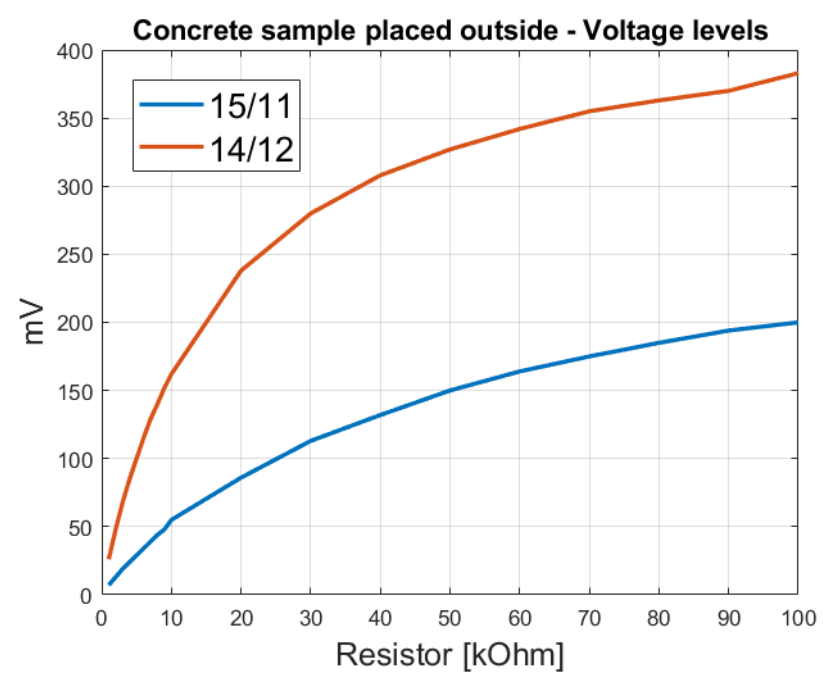

Fig. 27 Voltage measurements of the concrete placed inside (15/11) and outside (14/12) for a month.

In a real structure, which is much more robust - than the concrete sample, the authors believe sufficient energy should be available already 3-5 years into the service-life of the immersed tunnel.

The potential measurements from the corrosion sensors inside each separate location vary a lot, even between electrodes close to each other. This highlights the difficulties in the current corrosion assessment methods. Therefore, the authors are in the process of developing a new corrosion sensor based on electromechanical principles, that can be complementary to the CorroWatch sensor, see [30].

The powermanagement system did not work as expected, it was not possible to charge the long-term storage (LTS) capacitor. Instead, the short-term storage (STS) was used as LTS, and this worked fine. Even though the concrete battery circuitry (voltage source is series with an internal resistor) is more similar to a TEG, it was found out that when the PM was configured as solar cells it was more efficient. It is believed that 
the intrinsic capacitance of the concrete battery might be the issue.

To improve the existing systems, using the self-powered WSN will remove the need for extensive manual work and deliver the need amount of data for proper data interpretation.

The intended autonomous and self-sufficient monitoring system is shown in Fig. 28. Where the corrosion sensors are configured to Wireless Sensor Nodes.

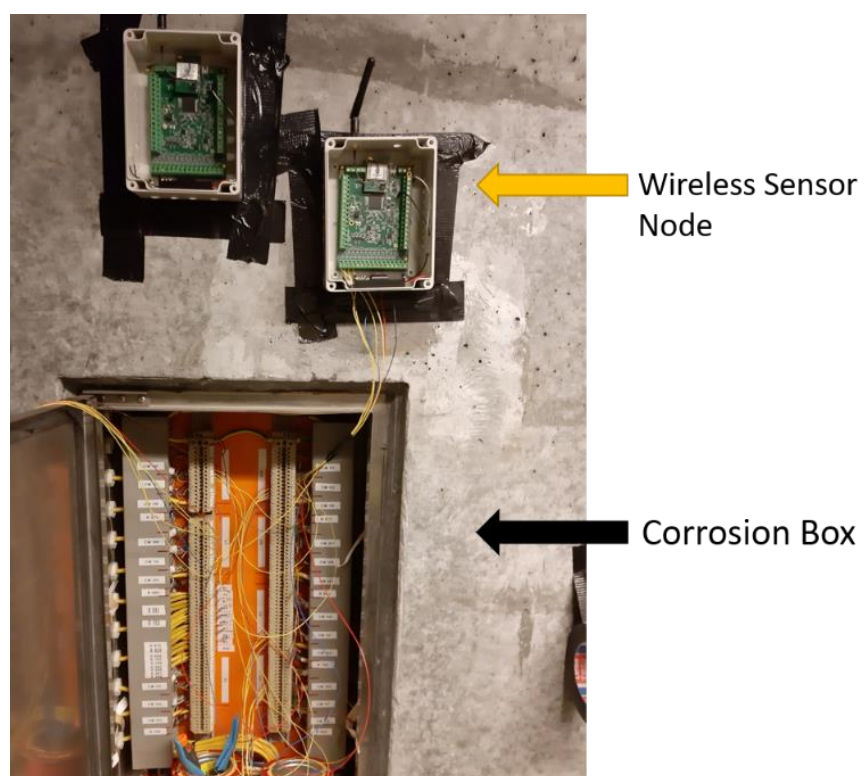

Fig. 28 Attaching the corrosion sensors to a self-powered WSN system in the immersed tunnel.

\section{CONCLUSION}

This paper investigated the possibilities of using corrosion energy (concrete battery) as a viable energy source for powering future corrosion sensors using WSN platforms. The results obtained from a real-world immersed tunnel shows that between $1 \mu \mathrm{W}-12.4 \mu \mathrm{W}$ of power is available (depending on the $\mathrm{CP}$ ) from the reinforcement steel and corrosion sensors. When the cathodic protection system (CP) is turned off, a slight decrease in the power levels can be observed. Nevertheless, the power outputs are still sufficient for the intended applications, where a wireless transmission of the potentials to a base-station are needed once every second month. The empirical results from the tunnel further show that most energy can be extracted from the sensor electrodes closest to the seawater. By using a commercial power management system, it is shown in the laboratory, that corrosion power can be harvested and stored in a supercapacitor for used in WSN.

For a long service life of the energy source, the steel reinforcements can be used as a large battery anode against a properly sized ERE20 or an equivalent probe.

\section{ACKNOWELEGMENT}

The authors would like to thank Klaus Lassen for the proofreading and Brian Lohse for his inputs. The project is funded by Innovation fund Denmark under File no.805300200B 


\section{BIBLIOGRAFI}

[1] J. Baber, "MOTT MACDONALD," [Online]. Available: https://www.mottmac.com/views/the-next-decade-will-markthe-immersed-tube-tunnels-coming-of-age. [Accessed 248 2021].

[2] Femern, "Fermern," [Online]. Available: https://femern.com/en/Tunnel/Facts-on-the-tunnel/Animmersed-tunnel. [Accessed 109 2021].

[3] N. International, "NACE INTERNATIONAL IMPACT," [Online]. Available: http://impact.nace.org/. [Accessed 153 2021].

[4] N. Winfield, "INPEPENDENT," [Online]. Available: https://www.independent.co.uk/news/world/europe/genoabridge-collapse-engineer-riccardo-morandi-warning-corrosionrust-concrete-a8498716.html. [Accessed 153 2021].

[5] M. Baker, A. Singhvi and P. Mazzei, "THE NEW YORK TIMES," [Online]. Available: https://www.nytimes.com/2021/06/26/us/miami-buildingcollapse-investigation.html. [Accessed 248 2021].

[6] H. Böhni, Corrosion in reinforced concrete structures, Boca Raton FL: CRC Press LLC, 2000.

[7] H. S. Wong, X. Y. Zhao, N. R. Buenfeld and L. W. Jin, "On the penetration of corrosion products from reinforcing steel into concrete due to chloride-induced corrosion," ELSEVIER Corro.Sci, vol. 52, no. 7, pp. 2469-2480, 2010.

[8] K. A. Soudki, T. Sherwood and S. Masoud, "FRP Repair of Corrosion- Damaged Reinforced Concrete Beams," University of Waterloo, Waterloo, ON, Canada, 2002.

[9] C. Christodoulou, G. Glass, S. Austin and C. Goodier, "Assessing the long term benefits of Impressed Current Cathodic protection," Elsevier Corro. Sci, vol. 52, no. 8, pp. 2671-2679, 2010.

[10] L. Yang, Techniques for corrosion monitoring, Cambridge UK: Woodhead Publishing Limited: Abington, 2008.

[11] M. Wischke, M. Masur, M. Kröner and P. Woias, "Vibration harvesting in traffic tunnels to power wireless sensor nodes," IOP SCIENCE Smart Materials and Structures, 2011.

[12] A. Moser, M. Erd, K. Cobry, M. Kroener and P. Woias, "Thermoelectric Energy Harvesting from Transient Ambient Temperature Gradients," Springer Link, vol. 41, pp. 16531661, 2012.

[13] S. A. Ouellette and M. D. Todd, "Cement Seawater Battery Energy Harvester for Marine infrastructure Monitoring," IEEE Sensors, vol. 14, no. 3, pp. 865-872, 2013.

[14] G. Qiao, "Corrosion Energy: A Novel Source to Power the Wireless Sensor," IEEE Sensors, vol. 13, no. 4, pp. 1141-1142, 2013.

[15] G. Qiao, G. Sun, H. Li and J. Qu, "Heterogeneous tiny energy: An appealing opportunity to power wireless sensor motes in a corrosive environment," ELSEVIER, vol. 131, pp. 87-96, 2014.

[16] E. Q. Zhang and L. Tang, "Rechargeable Concrete Battery," Sensors, vol. 11, no. 3, 2021.

[17] D. A. Jones, Principles and Prevention of Corrosion, Upper Saddle River, NJ: Prentice-Hall, Inc., 1996.

[18] I. Alabama Specialty Products, "Alspi.com," [Online]. Available: https://www.alspi.com/lprintro.htm. [Accessed 49 $1]$.

[19] FORCE TECHNOLOGY, "FORCE TECHNOLOGY CorroWatch," [Online]. Available: https://forcetechnology.com/-/media/force-technologymedia/pdf-files/0-to-4000/2522-corrowatch-installationinstructions.pdf. [Accessed 910 2021].

[20] FORCE TECHNOLOGY , "FORCE TECHNOLOGY," [Online]. Available: https://forcetechnology.com//media/force-technology-media/pdf-files/4001-to-4500/4088ere-20-en.pdf. [Accessed 109 2021].

[21] F. Technology, "FORCE Technology CorroZoa," [Online]. Available: https://forcetechnology.com/-/media/forcetechnology-media/pdf-files/4001-to-4500/4067-corrozoa.pdf. [Accessed 19 2021].

[22] H. -. W. Song and V. Saraswathy, "Corrosion Monitoring of Reinforced Concrete Structures - A Review," Int.J. Electrochem.Sci., pp. 1-28, 2007.

[23] TEXAS INSTRUMENTS, "ti.com," [Online]. Available: https://www.ti.com/product/BQ25504. [Accessed 910 2021].

[24] emmicroelectronic, "emmicroelectronic," [Online]. Available: https://www.emmicroelectronic.com/product/pmu-dc-energyharvesting-controller/em8500. [Accessed 109 2021].

[25] S. C. Paul, "The Role of Cracks and Chlorides in Corrosion of Reinforced Strain Hardening Cement-based Composite (R/SHCC)," Stellenbosch University - PHD Thesis, Stellenbosch, 2015.

[26] F. Orfei and C. Benedetta, "Vibrations powered LoRa sensor: An electromechanical energy harvester working on a real bridge," in 2016 IEEE SENSORS, Orlando, FL, USA, 2016.

[27] IMST, "https://wireless-solutions.de," WiMod by IMST, [Online]. Available: https://wireless-solutions.de/products/lorasolutions-by-imst/radio-modules/im282a-1/. [Accessed 249 2021].

[28] S. Kim, M. Lee and P. H. Chou, "Energy harvesting from anticorrosion power sources," in IEEE, La Jolla, Ca, USA, 2014.

[29] S. Dwars and C. O. Ubuane, "Using an impressed current cathodic protection system to power electrical appliances". US Patent US7951286B2, 2032007.

[30] J. H. Hire, S. Hosseini and F. Moradi, "Optimum PZT Patch Size for Corrosion Detection in Reinforced Concrete Using the Electromechanical Impedance technique," Sensors, vol. 21, no. $11,2021$. 


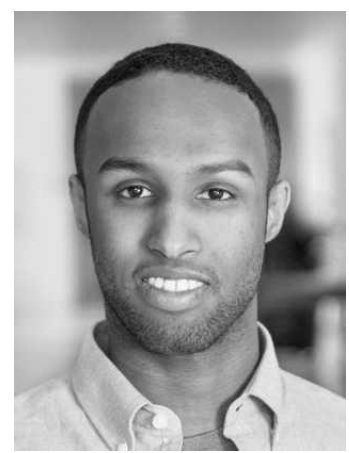

Jaamac Hassan Hire holds a Bachelor of Science and a Master of Science degree in electrical engineering from Aarhus University obtained in 2016 and 2018, respectively. His main interests during his studies have been sensors and transducers, ranging from electronic to optical system configurations. From 2018 to 2019 he has been working at FORCE Technology as a research engineer. Currently, he is pursuing his industrial Ph.D studies in the integrated nanoelectronics group, Aarhus University and FORCE Technology. His research area focuses on the development of new types of sustainable sensors for detection of early corrosion in reinforced concrete.

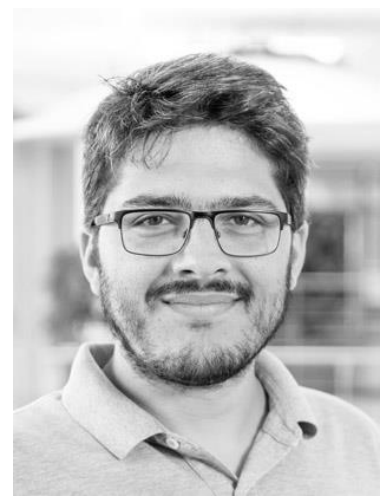

Nikolaos Agianniotis received the M.Sc. degree in electrical and computer engineering, with a specialization in electronics and systems, from the National Technical University of Athens (NTUA), Greece, in 2007 and the M.Sc. degree in electrical engineering and information technology, with a major in microelectronics and ASIC design, from ETH Zurich, Switzerland, in 2013. He has been involved in several electronic design projects in his professional career so far, ranging from Proof-of-Concept to product development and maintenance. He has international experience from Greece, Switzerland and Denmark. $\mathrm{He}$ is currently working as hardware engineer in the loT technology \& architecture department, IoT Data Services Innovation business unit of FORCE Technology in Denmark.

His interests include Internet of Things, sensors, wireless sensor networks, wireless communications, low-power design, and energy harvesting.

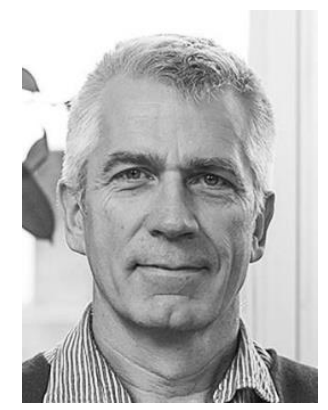

Brián Peter Kofoed is educated process engineer from 1984 from the Danish academy profession programme,

Copenhagen, with additional courses at the Danish Technical University, Lyngby, Copenhagen. Today, he is working as a project manager in the department of Building Consultancy Services for FORCE Technology in Denmark.

Area of specialisation in chemistry, especially in the areas of galvatechnique and corrosion of metals, and for the last 20 years in the area of design and control of

Cathodic protection of reinforcement in concrete, pipelines in soil/seawater and similar arrangements.

$\mathrm{He}$ has been involved in several larger projects in his professional career, ranging from developments of new intelligent embedded products such as $\mathrm{MnO} 2$-reference electrodes for concrete, early warning corrosion probes and resistivity probes for concrete structures. Besides this area he also developed a handheld NDT equipment for reinforcement corrosion using galvapulse technique. All probes and equipment that are used and sold worldwide today.

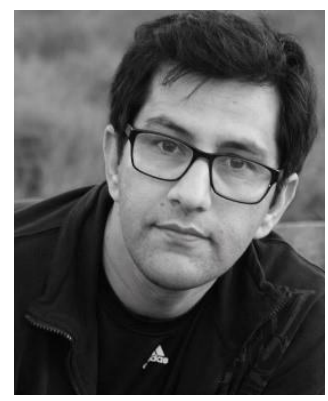

Farshad Moradi (Senior Member, IEEE) received the B.Sc. degree in electrical engineering from the Isfahan University of Technology, Isfahan, Iran, in 2001, the M.Sc. degree in electrical engineering from the Ferdowsi University of Mashhad, Mashhad, Iran, in 2005, a nd the Ph.D. degree in electrical engineering from the University of Oslo, Oslo, Norway, in 2011. From 2009 to 2010, he visited Nanoelectronic Laboratory, Purdue University, West Lafayette, IN, USA. He started his academic career as an Assistant Professor at the School of Engineering, Aarhus University, Aarhus, Denmark, where he is currently an Associate Professor with the Department of Engineering and the Director of the Integrated Circuit and Electronics Laboratory (ICELab). He is the author/coauthor of more than 80 journal articles and conference papers. His current research interests include ultralowpower integrated electronics from device to architecture. Dr. Moradi is also a reviewer of many journals and has been served on the technical committee of several conferences. He is also an Associate Editor of Integration, the VLSI Journal. 